\title{
Anterior Myocardial Infarction by ECG Finding
}

National Cancer Institute

\section{Source}

National Cancer Institute. Anterior Myocardial Infarction by ECG Finding. NCI Thesaurus.

Code C71069.

An electrocardiographic finding of pathologic Q waves in leads V3 and V4, which is

suggestive of myocardial infarction of the anterior wall of the left ventricle. (CDISC) 